\title{
ANALISA KONSUMSI DAYA SISTEM PELACAKAN POSISI MUATAN ROKET BERBASIS ARDUINO
}

\author{
Anak Agung Bagus Rama Windhu Putra ${ }^{1}$, Dewa Made Wiharta ${ }^{2}$, Nyoman Putra \\ Sastra $^{3}$ \\ ${ }^{123}$ Program Studi Teknik Elektro, Fakultas Teknik, Universitas Udayana

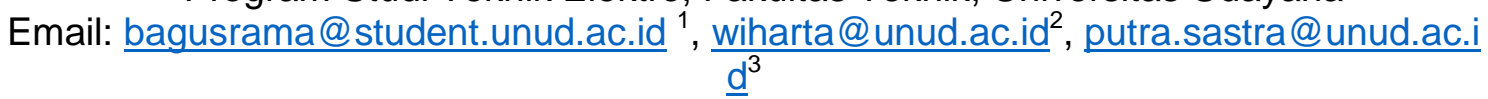

\begin{abstract}
ABSTRAK
Penelitian ini dilakukan untuk menguji konsumsi daya pada sistem pelacakan posisi payload roket berbasis arduino. Perangkat sistem terdiri dari Arduino Mega 2560, Sensor Compass, Sensor Barometer, Sensor GPS (Global Positioning System), LCD (Liquid Crystal Display) character, Xbee-Pro 900HP, dan dua buah motor servo. Pengujian dilakukan dengan menggunakan alat Digital Watt Meter yang mampu membaca tegangan, arus, dan daya yang digunakan pada sistem. Metode pengujian dengan cara mengamati digital watt meter pada saat sistem berjalan melakukan tracking pada payload roket. Interval waktu pengambilan data adalah 10 menit sekali selama 1 jam dan menghitung lama pemakaian, hingga baterai mencapai batas maksimal penggunaan. Penelitian telah berhasil dilakukan dan memperoleh hasil, saat pengujian interval waktu 1 jam, penggunaan daya oleh sistem adalah sebesar 0.470 Ah hingga tegangan baterai mencapai 11.8 volt dan daya rata-rata mencapai 5.56 watt. Pengujian lama waktu pemakaian dengan baterai Li-Po 1300 mAh selama 3 jam 56 menit hingga tegangan baterai mencapai 10.08 volt.
\end{abstract}

Kata Kunci: Arduino Mega 2560, GPS, Muatan Roket, Sistem Pelacak.

\section{ABSTRACT}

This study examines the power consumption of the Arduino-based rocket payload position tracking system. The system device consists of Arduino Mega 2560, Sensor Compass, Barometer Sensor, GPS (Global Positioning System) Sensor, LCD (Liquid Crystal Display) character, Xbee-Pro 900HP, and two servo motors. Testing is done using a Digital Watt Meter tool that is able to read the voltage, current, and power used in the system. Test method by observing digital watt meter when the system runs tracking the rocket payload. Data retrieval interval is once every 10 minutes for 1 hour and calculates usage time, until the battery reaches the maximum usage limit. This research has been carried out successfully. When test performs on interval of 1 hour, the power usage by the system is 0.470 Ah until the battery voltage reaches 11.8 volts and the average power reaches 5.56 watts. Usage time of a Li-Po $1300 \mathrm{mAh}$ battery is 3 hours 56 minutes until the battery voltage reaches 10.08 volts.

Keywords: Arduino Mega 2560, GPS, Rocket Payload, Tracking System.

\section{Pendahuluan}

Sistem pelacakan posisi muatan (payload) roket merupakan suatu sistem yang dilengkapi dengan kemampuan untuk mengarahkan suatu antena, yang terpasang pada sebuah Ground Control Station (GCS), menuju suatu muatan uji yang ditumpangkan pada sebuah roket.

Penelitian pada bidang sistem pelacak ini sedang dikembangkan. Pengembangan sistem antena pelacak untuk melacak unmanned aerial vehicle
(UAV) yang di teliti oleh Hanif Al Bana [1], pengembangan oleh Mahendra Budi [2] tentang penerapan kendali proporsional integratif derivatif (PID) pada sistem pelacak UAV dengan tujuan untuk menambah stabil sistem pelacak. Didalam penelitian [3] membahas cara menghitung durasi pemakaian alat.

Sistem pelacakan posisi payload ini telah dirancang dan direalisasikan, dimana komunikasi antara payload dan GCS dilakukan dengan menggunakan 
modul komunikasi Xbee-Pro 900HP. Agar payload dan GCS dapat berkomunikasi dengan baik, digunakan sebuah antena directional dengan gain yang besar pada arah tertentu. Pergerakan antena diatur dengan menggunakan motor servo yang dikendalikan oleh sebuah mikrokontroller Arduino Mega 2560. Kinerja sistem telah diujikan dan dilaporkan dalam [4].

Pelacakan payload roket ini dilakukan pada ruangan terbuka yang tidak memiliki sumber listrik. Kondisi seperti ini mengharuskan sistem pada GCS memiliki catu daya tersendiri. Sumber daya yang dipergunakan adalah baterai Lithium Polymer (Li-Po) dengan tegangan 12.6 volt dan kapasitas 1300 mAh. Dalam penelitian ini, dilakukan pengujian tentang konsumsi daya yang digunakan oleh sistem. Tujuan dari penelitian ini adalah untuk mengetahui rentang waktu pemakaian yang bisa disediakan oleh sistem tersebut.

\section{Kajian Pustaka}

\subsection{Arduino Mega 2560}

Arduino Mega 2560 digunakan karena memiliki lebih dari satu pin komunikasi serial. Pin komunikasi serial ini digunakan untuk sensor GPS, XbeePro $900 \mathrm{HP}$, dan untuk serial monitor. Arduino Mega 2560 mampu bekerja dengan tegangan input 7 sampai dengan 12 volt [5].

\subsection{Sensor Compass}

Sensor compass yang digunakan pada penelitian ini yaitu QMC5883L yang mampu memberikan sudut azimut dari sistem pelacak. Sensor ini mampu bekerja dengan tegangan 2.16 volt terendah dan tertinggi adalah 3.6 volt [6].

\subsection{Sensor Barometer}

Sensor barometer BMP180 mampu memberikan ketinggian dari sistem pelacak dan payload dengan satuan meter diatas permukaan laut [7].

\subsection{Liquid Crystal Display (LCD)}

LCD merupakan komponen elektronika yang mampu menampilkan data sensor dengan jumlah character yang ditampilkan 20 kolom $\times 4$ baris.

\subsection{Global Positioning System (GPS)}

Sensor GPS Ublox Neo-6M memberikan data koordinat latitude dan longtitude. Sensor GPS ini berkomunikasi dengan Arduino Mega 2560 melalui komunikasi serial.

\subsection{Xbee-Pro 900HP}

Modul elektronika ini berfungsi untuk mengkomunikasikan sistem pelacak dengan roket payload secara wireless. Xbee-Pro 900HP mampu berkomunikasi secara line-of-sight sejauh $6.5 \mathrm{~km}$ [8].

\subsection{Motor Servo}

Penelitian ini menggunakan dua buah servo yang memiliki fungsi yang berbeda. Servo pertama digunakan untuk pergerakan horizontal antena dan servo kedua digunakan untuk pergerakan vertikal.

\subsection{Digital Watt Meter}

Digital watt meter berguna untuk mengetahui besar arus yang digunakan pada rangkaian dan juga besar tegangan baterai. Watt meter ini mampu membaca hingga tegangan maksimal 60 volt dan arus maksimal 100 ampere dc [9].

\subsection{Baterai Tattu 3 sel 1300 mAh}

Baterai dengan kapasistas 1300 $\mathrm{mAh}$ ini memiliki tegangan maksimum 12.6 volt dan tegangan minimum 10.08 volt. Penggunaan baterai tidak disarankan kurang dari 10.08 volt, karena akan mengurangi umur penggunaan baterai. Untuk menghitung kapasitas maksimal penggunaan baterai, tegangan minimum baterai, dan estimasi penggunaan baterai menggunakan persamaan berikut [10].

$$
\text { Amaks }=\text { Cbatt }-20 \%
$$




$$
\text { VMin }=\text { Vsel } * 3 \text { sel }
$$

Persamaan (1) digunakan untuk mengetahui kapasitas maksimal penggunaan baterai. Amaks pada persamaan (1) merupakan kapasitas maksimum baterai yang digunakan, Cbatt adalah kapasitas total baterai, dan 20\% merupakan ketentuan batas penggunaan baterai. Persamaan (2) digunakan untuk menghitung tegangan minimum yang dicapai baterai. Vsel pada persamaan (2) merupakan tegangan minimum baterai per sel nya yaitu 3.36 volt, pengalian 3 sel dikarenakan baterai yang digunakan memiliki 3 sel. Penelitian ini juga menguji estimasi durasi penggunaan baterai $E p$ dengan persamaan berikut [3].

$$
E p=\frac{\text { Kapasitas }}{\text { Penggunaan }}
$$

Persamaan (3) tersebut digunakan untuk menghitung estimasi penggunaan baterai. Kapasitas merupakan kapasitas total baterai dengan satuan mAh dan Penggunaan merupakan daya rata-rata yang digunakan baterai selama satu jam.

\section{Metodologi Penelitian}

\subsection{Perancangan Perangkat Keras}

Perangkat keras dari penelitian ini ditampilkan pada blok diagram pada Gambar 1. Dalam pengujian, digital watt meter dirangkai seri antara baterai dengan rangkaian sistem pelacak. Penelitian ini menggunakan baterai dengan tegangan maksimum adalah 12.6 volt.

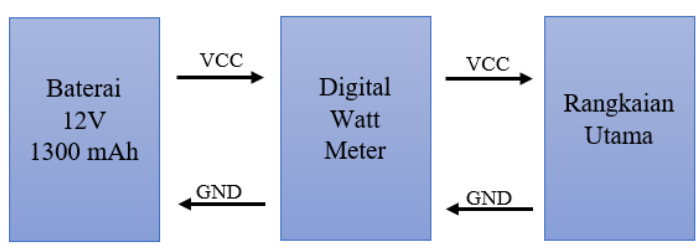

Gambar 1 Diagram Blok Perancangan Perangkat Keras
Baterai 12 volt $1300 \mathrm{mAh}$ dihubungkan dengan digital watt meter agar dapat mengetahui nilai pengukuran tegangan, arus, dan daya yang digunakan pada rangkaian utama. Rangkaian utama tersebut merupakan sistem pelacak muatan roket dengan skema rangkaian yang ditampilkan pada Gambar 2.

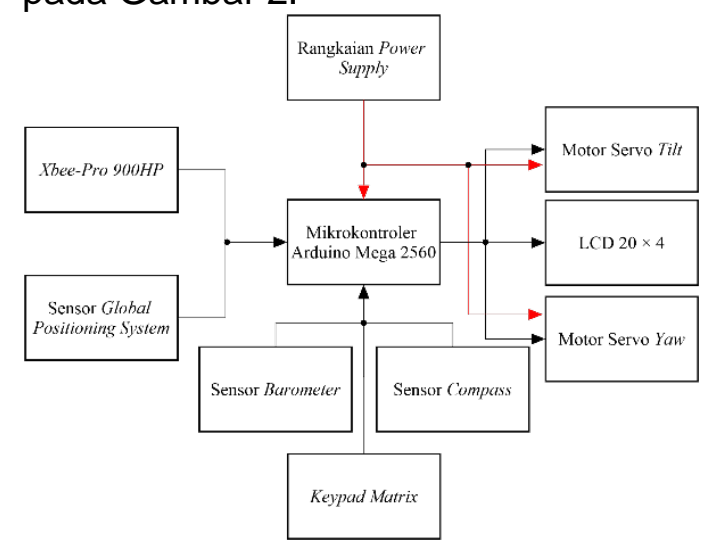

Gambar 2 Skema Rangkaian Sistem Pelacak

Garis merah menggambarkan perangkat yang terhubung langsung dengan Power Supply atau catu daya baterai, sedangkan perangkat lainnya mengambil sumber daya langsung dari Arduino Mega 2560.

\section{Hasil Dan Pembahasan}

\subsection{Realisasi Hasil Perancangan}

Pengujian daya sistem pelacak didukung dengan timer pada handphone yang digunakan untuk mengukur waktu. Realisasi pengujian daya sistem pelacak ditunjukan pada Gambar 3 berikut ini.

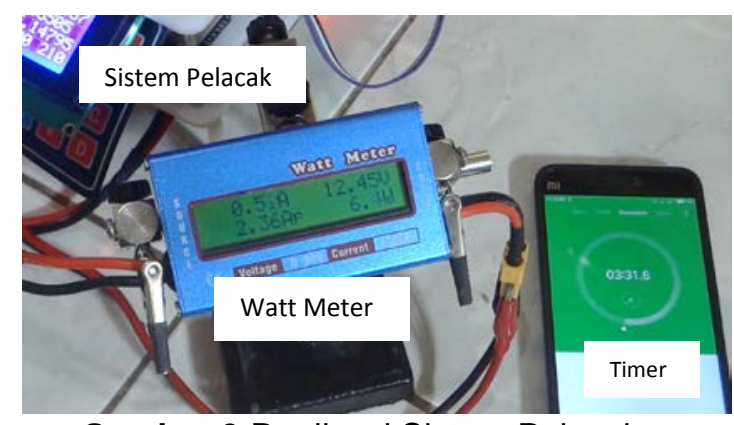

Gambar 3 Realisasi Sistem Pelacak

Sistem pelacak dan muatan uji roket yang digunakan pada penelitian 
ini sama seperti yang digunakan pada penelitian [4]. Tampak sistem pelacak dan muatan uji roket ditampilkan pada Gambar 4 berikut.

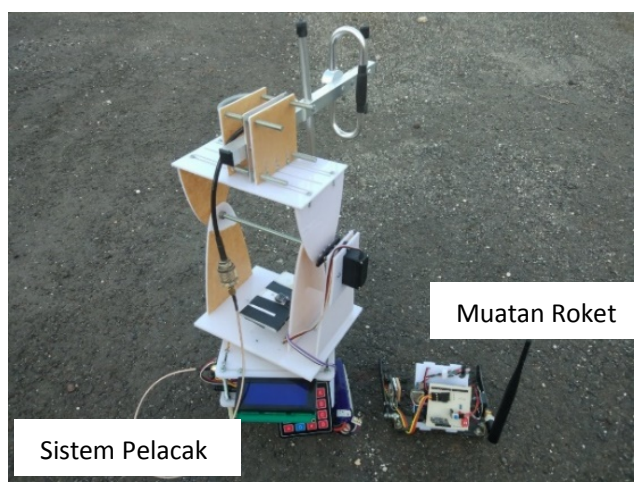

Gambar 4 Sistem Pelacak Dan Muatan Roket Yang Digunakan

Pengujian untuk mendapatkan estimasi waktu penggunaan baterai dan pengujian pemakaian berkelanjutan sama-sama menggunakan timer sebagai penghitung waktu.

\subsection{Pembahasan}

Pembahasan

pengujian

dilakukan dengan menghitung estimasi penggunaan baterai dengan cara menghidupkan perangkat selama satu jam dan menghitung rata-rata daya yang digunakan. Pengujian kedua dilakukan dengan menghidupkan perangkat hingga mencapai tegangan baterai terendah.

\subsubsection{Pengujian Estimasi Durasi}

Pengukuran dilakukan dalam kondisi sistem pelacak berada dalam kondisi aktif dalam melakukan pelacakan dan pergerakan servo. Pengukuran dilakukan dengan mengambil data tegangan (volt), arus (ampere), dan daya (watt) pada interval waktu 10 menit. Hasil Pengukuran ditunjukkan pada Tabel 1.

Tabel 1. Hasil Pengukuran Tegangan dan Arus

\begin{tabular}{|c|c|c|c|c|c|c|}
\hline \multirow{2}{*}{ Parameter } & \multicolumn{7}{|c|}{ Waktu (menit) } \\
\cline { 2 - 7 } & 10 & 20 & 30 & 40 & 50 & 60 \\
\hline $\begin{array}{c}\text { Tegangan } \\
\text { (Volt) }\end{array}$ & 12.38 & 12.27 & 12.1 & 12.06 & 11.89 & 11.81 \\
\hline $\begin{array}{c}\text { Arus } \\
\text { (Ampere) }\end{array}$ & 0.48 & 0.42 & 0.51 & 0.48 & 0.42 & 0.51 \\
\hline $\begin{array}{c}\text { Daya } \\
\text { (Watt) }\end{array}$ & 5.9 & 5.1 & 6.1 & 5.8 & 5 & 6 \\
\hline
\end{tabular}

Penelitian ini menggunakan baterai jenis Li-Po 3 sel $11.1-12,6$ volt 1300 mAh. Baterai ini dengan keadaan penuh memiliki tegangan 12.6 volt yang berarti 4,2 volt untuk tiap selnya. Berdasarkan buku panduan penggunaan baterai [10], Baterai tidak boleh digunakan kurang dari $20 \%$ dari kapasitas baterai total atau kurang dari 3.36 volt per sel. Berikut perhitungan untuk baterai Li-Po 3 sel 1300 mAh. Dengan persamaan (1) dan (2) maka didapat kapasitas maksimum dan tegangan minimum yang dicapai baterai.

$$
\begin{aligned}
\text { Amaks } & =1300 \mathrm{mAh}-20 \% \\
& =1040 \mathrm{mAh} \\
\text { VMin } & =3.36 \mathrm{~V} * 3 \mathrm{sel} \\
& =10.08 \mathrm{Volt}
\end{aligned}
$$

Perhitungan persamaan (1) dan (2) tersebut mendapatkan hasil bahwa kapasitas maksimum baterai yang digunakan adalah sebesar $1040 \mathrm{mAh}$ dan tegangan minimum yang dicapai baterai adalah sebesar 10.08 volt.

Berdasarkan pengujian daya sistem pelacak, dengan cara menghidupkan sistem pelacak dalam posisi aktif, didapatkan penggunaan arus rata-rata alat dalam 1 jam adalah $0.470 \mathrm{Ah}$, dan tegangan baterai pada waktu 1 jam adalah 11.8 volt. Berdasarkan data tersebut dapat dihitung estimasi penggunaan baterai dengan persamaan (3).

$$
\begin{aligned}
E p & =\frac{1040 \mathrm{mAh}}{470 \mathrm{mAh}} \\
& =2.2 \mathrm{jam}
\end{aligned}
$$

Perhitungan dengan persamaan (3) menghasilkan estimasi waktu penggunaan sebesar 2.2 jam atau setara dengan 2 jam 12 menit. 1040 mAh merupakan kapasitas maksimum yang dapat digunakan, sedangkan 470 mAh merupakan daya rata-rata yang digunakan baterai selama satu jam pengujian.

\subsubsection{Pengujian Durasi Sebenarnya}


Pengujian durasi waktu penggunaan baterai Li-Po 3 sel 1300 mAh dilakukan dengan cara pemakaian berkelanjutan. Pengujian dilakukan dengan cara menggunakan baterai dari tegangan maksimum 12.6 volt hingga 10.08 volt. Hasil pengujian ditampilkan pada grafik Gambar 5.
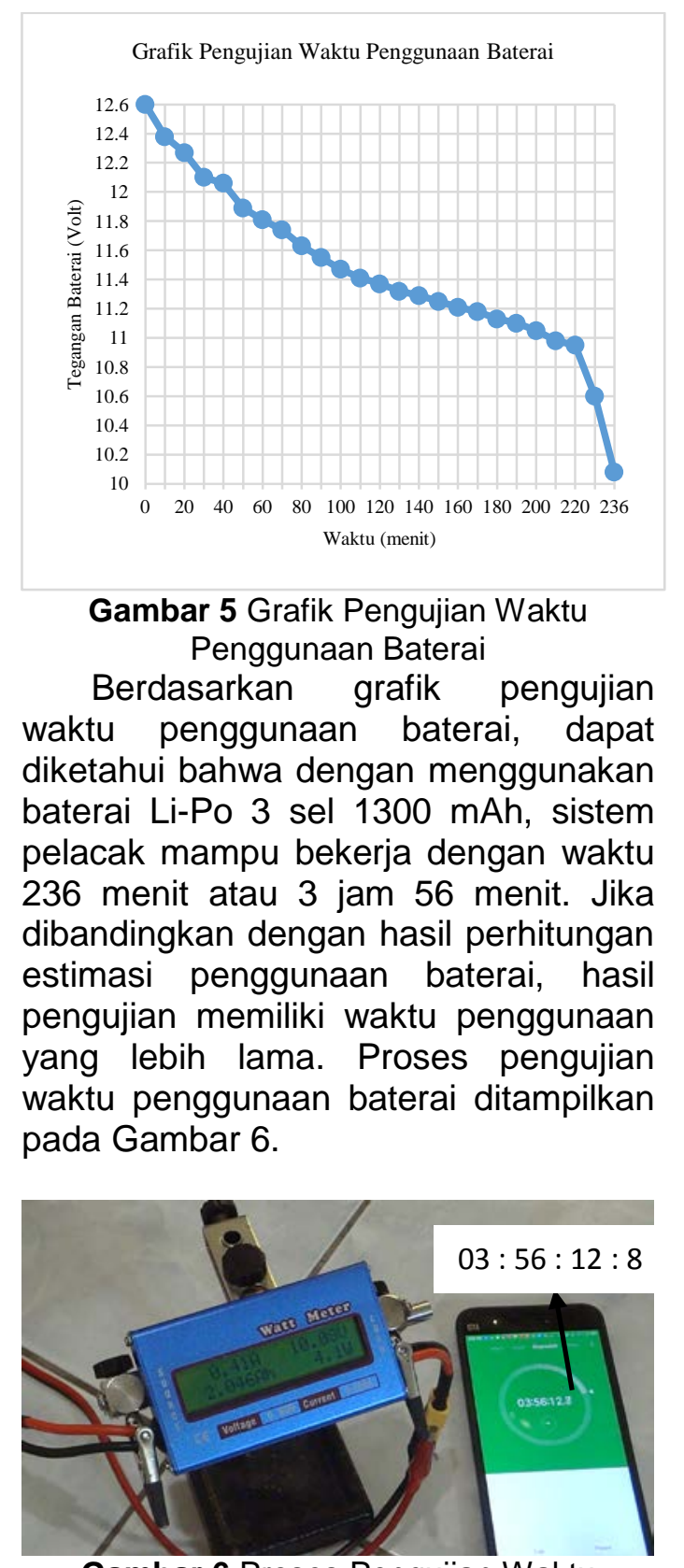

Gambar 6 Proses Pengujian Waktu Penggunaan Baterai

Pengujian secara berkelanjutan ini dilakukan hingga baterai mencapai tengangan minimumnya yaitu 10.08 volt. Pada Gambar 6 menampilkan pengujian hingga tegangan minimum mendapatkan waktu 3 jam 56 menit dengan perhitungan timer pada handphone.

\section{Kesimpulan}

Simpulan yang dapat ditarik dari penelitian yang telah dilakukan tersebut adalah bahwa dengan baterai Li-Po 3 sel 12.6 volt $1300 \mathrm{mAh}$, sistem pelacakan posisi muatan roket berbasis arduino mampu hidup dengan estimasi waktu 2.2 jam atau 2 jam 12 menit. Berdasarkan pengujian sebenarnya, sistem mampu hidup hingga 3 jam 56 menit hingga mencapai titik terendah tegangan baterai yang diperbolehkan.

\section{Daftar Pustaka}

[1] M. H. Al Bana and R. Mardiyanto, Pengembangan Antenna Tracker Berbasis Global Positionning System (GPS) untuk Komunikasi Pesawat Tanpa Awak, Surabaya: Institut Teknologi Sepuluh Nopember, 2017.

[2] M. B. Nugraha and R. Sumiharto, Penerapan Sistem Kendali PID pada Antena Pendeteksi Koordinat Posisi UAV, Yogyakarta: Universitas Gadjah Mada, 2015.

[3] P. Diana, Perancangan Modul Pembelajaran Huruf Braille Berbasis Mikrokontroler Untuk Membantu Proses Belajar Disabilitas Netra, Bukit Jimbaran: Universitas Udayana, 2017.

[4] D. W. A.A.B. R. Windhu Putra and N. P. Sastra, "GPS-Based Rocket Payload Position Tracking System," submitted to Serbian Journal of Electrical Engineering, 2018.

[5] Arduino, "Arduino Mega 2560 Rev3," Electronics, 2018. [Online]. Available: https://store.arduino.cc/arduino- 
mega-2560-rev3. [Accessed 27 August 2018].

[6] OSOYOO, 3-Axis Magnetic Sensor QMC5883L Datasheet, Canada: OSOYOO, 2017.

[7] Robotpark, "BMP180 Digital Barometric Pressure Sensor," 2017. [Online]. Available: http://www.robotpark.com/BMP18 0 -Digital-Barometric-Pressure-

Sensor ?search=bmp180. [Accessed 27 August 2018].

[8] Digi, User Guide XBee-Pro 900HP/XSC RF Modules, Digi
International Inc, 2017.

[9] G.T.Power Rc, High Precision Watt Meter and Power Analyzer Datasheet, Hong Kong: G.T.Power Rc, 2017.

[10] Tattu, Important Safety Instructions And Warnings, Dublin: Tattu, 2018. 